\title{
Using electronic medical records analysis to investigate the effectiveness of lifestyle programs in real-world primary care is challenging: a case study in diabetes mellitus
}

Citation for published version (APA):

Linmans, J. J., Viechtbauer, W., Koppenaal, T., Spigt, M., \& Knottnerus, J. A. (2012). Using electronic medical records analysis to investigate the effectiveness of lifestyle programs in real-world primary care is challenging: a case study in diabetes mellitus. Journal of Clinical Epidemiology, 65(7), 785-792.

https://doi.org/10.1016/j.jclinepi.2012.01.010

Document status and date:

Published: 01/07/2012

DOI:

10.1016/j.jclinepi.2012.01.010

Document Version:

Publisher's PDF, also known as Version of record

Document license:

Taverne

Please check the document version of this publication:

- A submitted manuscript is the version of the article upon submission and before peer-review. There can be important differences between the submitted version and the official published version of record. People interested in the research are advised to contact the author for the final version of the publication, or visit the DOI to the publisher's website.

- The final author version and the galley proof are versions of the publication after peer review.

- The final published version features the final layout of the paper including the volume, issue and page numbers.

Link to publication

\footnotetext{
General rights rights.

- You may freely distribute the URL identifying the publication in the public portal. please follow below link for the End User Agreement:

www.umlib.nl/taverne-license

Take down policy

If you believe that this document breaches copyright please contact us at:

repository@maastrichtuniversity.nl

providing details and we will investigate your claim.
}

Copyright and moral rights for the publications made accessible in the public portal are retained by the authors and/or other copyright owners and it is a condition of accessing publications that users recognise and abide by the legal requirements associated with these

- Users may download and print one copy of any publication from the public portal for the purpose of private study or research.

- You may not further distribute the material or use it for any profit-making activity or commercial gain

If the publication is distributed under the terms of Article 25fa of the Dutch Copyright Act, indicated by the "Taverne" license above, 


\title{
Using electronic medical records analysis to investigate the effectiveness of lifestyle programs in real-world primary care is challenging: a case study in diabetes mellitus
}

\author{
Joris J. Linmans ${ }^{\mathrm{a}}$,*, Wolfgang Viechtbauer ${ }^{\mathrm{b}}$, Tjarco Koppenaal ${ }^{\mathrm{c}}$, Mark Spigt ${ }^{\mathrm{a}}$, \\ J. André Knottnerus ${ }^{\mathrm{a}}$ \\ ${ }^{a}$ Department of General Practice, CAPHRI, Maastricht University, P.O. Box 616, 6200 MD, Maastricht, The Netherlands \\ ${ }^{\mathrm{b}}$ Department of Psychiatry and Neuropsychology, MHeNS, Maastricht University, P.O. Box 616, 6200 MD, Maastricht, The Netherlands \\ ${ }^{\mathrm{c}}$ Corporation of Primary Health Care Centers Eindhoven, Eindhoven, The Netherlands
}

Accepted 22 January 2012; Published online 3 May 2012

\begin{abstract}
Objective: The increasing prevalence of diabetes suggests a gap between real world and controlled trial effectiveness of lifestyle interventions, but real-world investigations are rare. Electronic medical registration facilitates research on real-world effectiveness, although such investigations may require specific methodology and statistics. We investigated the effects of real-world primary care for patients with type 2 diabetes mellitus (T2DM).

Study Design and Setting: We used medical records of patients $(n=2,549)$ with T2DM from 10 primary health care centers. A mixedeffects regression model for repeated measurements was used to evaluate the changes in weight and Hemoglobin A1c (HbA1c) over time.

Results: There was no statistically significant change in weight $(+0.07 \mathrm{~kg}, P=0.832)$ and $\mathrm{HbA1c}(+0.03 \%, P=0.657)$ during the observation period of 972 days. Most patients maintained their physical activity level (70\%), and $54 \%$ had an insufficient activity level. The variability in the course of weight and HbA1c was because of differences between patients and not between health care providers.

Conclusion: Despite effective lifestyle interventions in controlled trial settings, we found that real-world primary care is only able to stabilize weight and HbA1c in patients with T2DM over time. Medical registration can be used to monitor the actual effectiveness of interventions in primary care. (C) 2012 Elsevier Inc. All rights reserved.
\end{abstract}

Keywords: Primary health care; Electronic health records; Diabetes mellitus, type 2; Health care quality, access, and evaluation; Lifestyle; Translational research

\section{Introduction}

It is well known that the number of patients diagnosed with type 2 diabetes mellitus (T2DM) has grown considerably and that T2DM has become a substantial medical and financial problem [1-3]. T2DM has high morbidity and mortality rates because of nephropathy, retinopathy, neuropathy, and increased risk of cardiovascular disease. Of all deaths, $5.2 \%$ are estimated to be attributable to diabetes in general, projecting it to be the fifth leading cause of death in the world [4].

Weight loss and increases in physical activity (PA) are considered to be the cornerstones in the prevention and treatment of T2DM [5-8]. Intensive lifestyle interventions

* Corresponding author. Tel.: +31-(0)-43-388-4186; fax: +31-(0)-43361-9344.

E-mail address: joris.linmans@maastrichtuniversity.nl (J.J. Linmans). have been shown to decrease the likelihood of developing T2DM in patients with prediabetes, improve glycemic control, and reduce risk factors for cardiovascular disease [9-11]. In addition, marked weight loss after bariatric surgery can in fact produce remission of T2DM [12].

Considering the availability of lifestyle programs and attempts to implement these programs into primary health care [13-21], one would like to observe a decrease in the prevalence of T2DM. However, the prevalence of T2DM is still increasing rapidly [1-3]. This may imply that care outside the randomized trial setting is not as effective as in real-world settings and/or that translation of evidence into usual primary care is difficult [22]. Investigating the real-world effects of lifestyle interventions in primary care is often not possible because of the fact that outcome measures are not routinely recorded. Many randomized trials have a "usual care" control group, but this may not be an appropriate reflection of the real usual care as people can act differently in a research setting [23]. In addition, 


\section{What is new?}

- There is an urgent need of lifestyle programs developed and proven effective in primary care to really intervene in the worldwide diabetes pandemic.

- More studies should be performed in primary care networks with solid medical registration systems.

- Primary care is only able to stabilize weight and Hemoglobin A1c in patients with type 2 diabetes mellitus.

- Most patients with T2DM have an insufficient physical activity level.

- Translating evidence from lifestyle programs from research settings into real-world settings remains challenging.

randomized trials often use highly selected populations [24-26]. Therefore, studies from real-world primary care are needed. To be able to intervene in the diabetes pandemic, we need to solve the puzzle of the evidence gap between effectiveness in trial settings and primary care settings.

Because of electronic medical registration in primary care, detailed information about the quality of care for patients with T2DM becomes increasingly available [27-29]. Studies using these databases can provide a realistic benchmark of the current effects of T2DM primary health care, so that the magnitude of the challenge to improve lifestyle becomes clear for health care providers, researchers, and policy makers.

We examined a cohort of approximately 2,500 patients with T2DM in a real-world primary care setting over a period of 972 days. The aim of the study was to determine the effects of the currently provided care on the course of weight and Hemoglobin A1c (HbA1c) to illustrate a part of the puzzle of translating evidence into daily practice. In addition, we propose a statistical solution to analyze the hierarchical data in the course of time.

\section{Methods}

\subsection{Setting}

We conducted the study in collaboration with Corporation of Primary Health Care Centers, Eindhoven (SGE). SGE includes 10 primary health care centers, 45 general practitioners, and approximately 60,000 patients in a semi-large city in the Netherlands. We performed a retrospective longitudinal analysis among patients with T2DM receiving usual care at one of the SGE centers using electronic primary care medical records for data abstraction.

\subsection{Description of the diabetes management program in usual care}

In SGE, a diabetes management program was implemented in 2007. According to this program, patients have regular checks four times per year; every 3 months with a diabetes practice nurse (DPN) (three times per year) and annually with the general practitioner. Several variables are measured at every visit, including blood pressure, weight, body mass index (BMI), fasting glucose level (capillary blood), smoking and alcohol habits, disease experience, and medication and diet compliance. During the diabetes checkups, the DPN also asks the patients about their PA. Based on the responses, patients are classified into three levels: "Healthy" (Dutch Standard for Healthy Physical Activity), meaning that the patient moves 5 days per week 30 minutes at moderate intensity (e.g., dancing, gardening, and brisk walking), "Deficient," which means being less active than those in the "Healthy" level, and "Sportive," meaning more active than those in the "Healthy" level and that the patient moves at least three times per week 20 minutes at high intensity (e.g., intensive fitness and intensive cycling). Once per year, HbA1c level, blood lipid levels, renal function, eyes, feet, and abdominal circumference are checked. When necessary, extra checkups can be performed in between the regular quarterly consultations.

Every person with diabetes receives lifestyle advice from the DPN. In the first months after diagnosis and when insulin treatment is started, patients with T2DM go to a dietician for a consultation on nutritional advice. After consulting the dietician, nutritional advice is provided by the DPN during the regular checks. People with a BMI $>25 \mathrm{~kg} / \mathrm{m}^{2}$ are encouraged to lose weight. If patients are motivated, they are referred to a physiotherapist to assist them in increasing their PA level. The physiotherapists, employed by SGE, have been trained in motivational interviewing and specific PA programs for diabetics.

\subsection{Study population and data collection}

Data on diabetes indicators measured during the quarterly checks were collected from the 1st of January 2007 (implementation of the diabetes management program) to the 1st of September 2009 and abstracted from electronic primary care medical records. Study subjects were selected using the International Classification of Primary Carecodes T90 (diabetes), T90.1 (type 1 diabetes), and T90.2 (type 2 diabetes) (Fig. 1). We only used patients from nine health care centers as at the time, one center had just started and provided diabetes care for only five patients (only two of which had usable data). Patients who received diabetes care primarily in the hospital (medical specialist) had an additional code in the general practitioner's registration system and were excluded from analyses, as well as patients with type 1 diabetes. Patients with code T90 could be with either type 1 or type 2 diabetes. However, if 


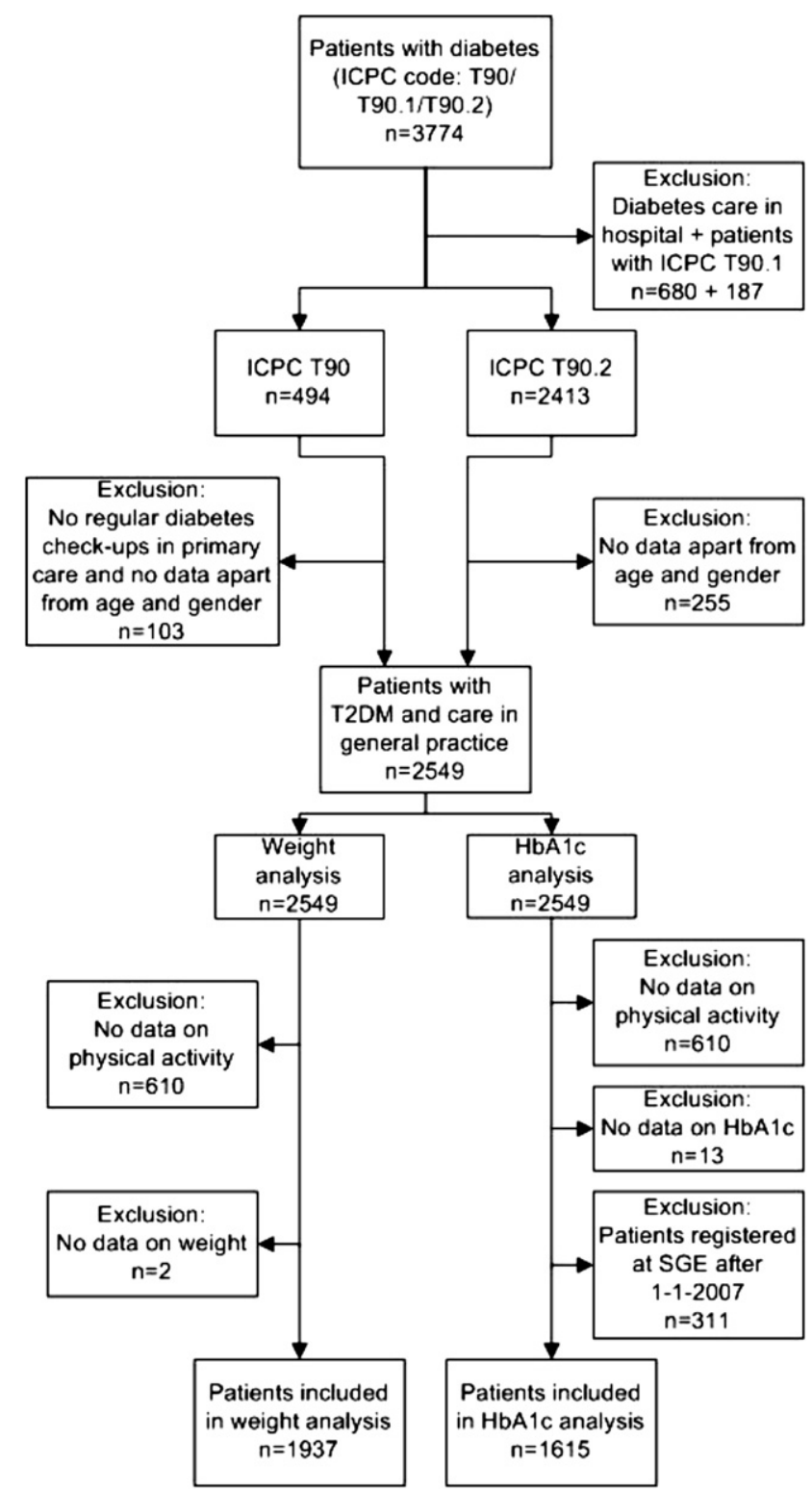

Fig. 1. Flow of included patients for weight analysis and Hemoglobin Alc (HbA1c) analysis (ICPC: International Classification of Primary Care).

patients had regular diabetes checkups in primary care and had no additional code for hospital diabetes care, they were included in the analyses, and we assumed that these patients had T2DM. In addition, we excluded patients for whom we had no more data than age and gender. The individual observation periods vary as patients could have been diagnosed with T2DM later than January 2007 or could have moved or died before September 2009.

\subsection{Statistical analysis}

We first examined the data visually, by plotting the repeated measurements of weight and $\mathrm{HbA} 1 \mathrm{c}$ over time. A loess smoother [30] was added to the plot to provide a model-free summary of the overall trend in the data. We then examined individual trajectories for the subjects. For weight, the repeated measurements appeared to be well approximated by linear trends. This also was true for the $\mathrm{HbA} 1 \mathrm{c}$ measurements for most patients. However, a number of patients who were registered after January 1, 2007 showed a rapid decline in HbAlc levels at the start (a hockey-stick phenomenon), probably because of the commencement of medical treatment. Neither a linear nor a quadratic trend approximated the HbA1c measurements adequately for these individuals. Moreover, because the change point varied for these individuals and the use of a random change point model proved not suitable, we decided to analyze the HbA1c measurements only for those patients with a registration date at SGE before January 1, 2007.

To account for the hierarchical structure of the data (repeated measurements nested within patients, which in turn were nested within general practitioners, which in turn were nested within health care centers) and to properly distinguish within-person changes and between-person differences, we used a mixed-effects regression model for repeated measurements to evaluate the changes in weight and $\mathrm{HbA1c}$ in the course of time [31]. The analyses were conducted with the statistical software R (v 2.14.1; R foundation for Statistical Computing, Vienna, Austria), using the nlme package [32]. The primary predictor of interest was time (i.e., the number of days within the follow-up period subsequent to the first measurement day within the follow-up period), which was included in the model as a time-varying covariate. Age (at the first measurement occasion), gender, initial PA level, and the day of the first measurement within the follow-up period for each individual patient were taken into account as time invariant covariates. Because we were studying an open cohort in a natural setting, we coded time in an absolute manner. For example, the day of the first measurements would be coded as 15 for a patient measured for the first time on January 16, 2007 (January 1, 2007 corresponds to day 0) and subsequent measurements are then coded as the number of days passed since that day (e.g., 64 days for a second measurement taken on March 20, 2007).

Moreover, we selected the first and the last observation of the initial PA level (three categories) within each person's individual follow-up period and used the transition between both observations to define nine categories of changes in PA level (PA-change level). We then examined whether age, gender, and the PA-change level interacted with time, that is, whether changes in weight and $\mathrm{HbAlc}$ differed as a function of these variables. For age, polynomials up to the third degree also were examined to determine whether this variable exerted a nonlinear influence on the dependent variable. Finally, we included random effects for the intercept and the slope of time on the person, general practitioner, and center levels of the hierarchical model. However, because the variability in the intercepts 
and slopes was essentially zero at the center level, we dropped this level from the model.

\section{Results}

During the observation period of 972 days, we included 2,549 patients with T2DM (Fig. 1). The baseline characteristics of these 2,549 patients at study entry are shown in Table 1 . The percentages of patients in the nine categories of changes in PA level are displayed in Fig. 2. This figure shows that over $51 \%(40.1+0.8+10.2)$ of the patients had a "Deficient" initial PA level and 54\% (40.1+ $1.4+12.8)$ had a "Deficient" level at the end of the observational period. In total, $12 \%$ of the patients increased their PA level, $17 \%$ decreased, and $70 \%$ maintained their PA level. Only 7\% had a "Sportive" initial PA level, and only $2 \%$ increased their activity to a "Sportive" PA level, whereas 5\% decreased their activity to a lower level than "Sportive." All measurements of weight and HbA1c over time are plotted in Figs. 3 and 4. Four individual trajectories are added to the figures for illustration purposes. A loess smoother was added to visualize the model-free overall trend of the weight and HbAlc data. The smoothers show that the overall trend is practically horizontal.

For the analyses of the changes in weight over time, we included 1,937 patients (Fig. 1). The results from the multilevel model are shown in Table 2. The estimated average weight for 70-year old male patients (reference patient) with an initial PA level of "Deficient" was $88.67 \mathrm{~kg}$ at the beginning of the observation period. Female patients were $7.92 \mathrm{~kg}$ lighter than male patients $(P<0.001)$. Also, younger patients were heavier compared with the elderly $(+3.98 \mathrm{~kg}$ for every 10 years below the age of 70; $P<$ 0.001). Individuals with a "Deficient" initial PA level were $3.77 \mathrm{~kg}$ heavier than those with a "Healthy" initial PA level $(P<0.001)$. The initial weight of the patients did not

Table 1. Patient characteristics at study entry

\begin{tabular}{lc}
\hline Characteristics & Study entry $(\boldsymbol{n}=\mathbf{2 , 5 4 9 )}$ \\
\hline Age, years & $68.2(12.4)$ \\
Gender & \\
$\quad$ Male & $1,226(48.1 \%)$ \\
$\quad$ Female & $1,323(51.9 \%)$ \\
Smoking & $386(15.1 \%)$ \\
Weight, kg & $83.9(26.9)$ \\
Systolic blood pressure, mm Hg & $143.7(20.3)$ \\
Abdominal circumference, cm & $102.7(11.8)$ \\
Total cholesterol, mmol/I & $4.6(1.1)$ \\
Body length, cm & $167.4(10.2)$ \\
BMI, kg/m ${ }^{2}$ & $30.0(5.4)$ \\
Fasting glucose, mmol/l & $7.7(2.3)$ \\
HbAlc, \% & $6.8(1.2)$ \\
Creatinine, umol// & $79.1(21.3)$ \\
LDL cholesterol, mmol/l & $2.9(1.0)$ \\
\hline
\end{tabular}

Abbreviations: BMI, body mass index; HbAlc, Hemoglobin A1c; LDL, low-density lipoprotein.

Data are presented as means (SD), unless otherwise stated.

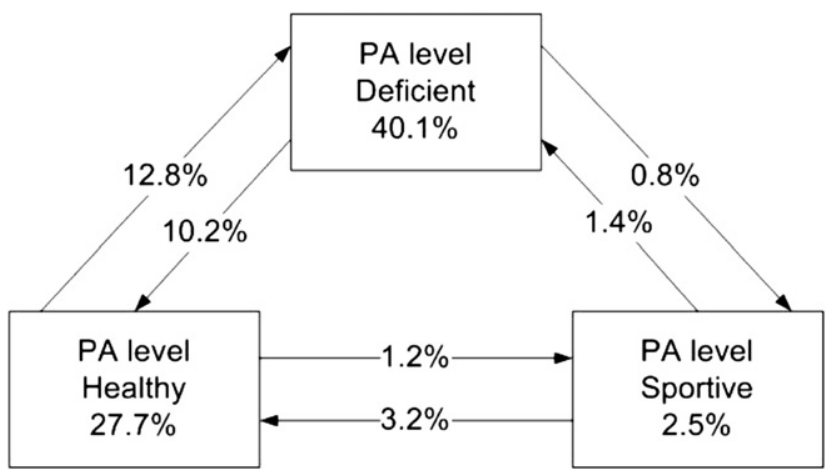

Fig. 2. Percentages of patients in the nine categories of changes in physical activity (PA) level. (1) Healthy: moving 5 days per week at least 30 minutes at moderate intensity (e.g., dancing, gardening, and brisk walking); (2) Deficient: being less active than the patients in the Healthy level; (3) Sportive: moving at least three times per week 20 minutes at high intensity (e.g., intensive fitness and intensive cycling). The percentages of patients who maintain their PA level are presented within the squares. Data on PA levels were unavailable for 610 patients.

depend on the day of the first measurement during the observation period $(P=0.537)$.

On average, weight did not change statistically significant during the observation period $(+0.07 \mathrm{~kg}$ over 972 days; $P=0.832)$. The change in weight was not significantly different for female patients $(P=0.868)$ when compared with males. However, age showed a quadratic interaction with the course of weight during the observation period $(P=0.024)$. In particular, younger $(\leq 29$ years $)$ and elderly patients $(\geq 71$ years) tended to lose more (or gain

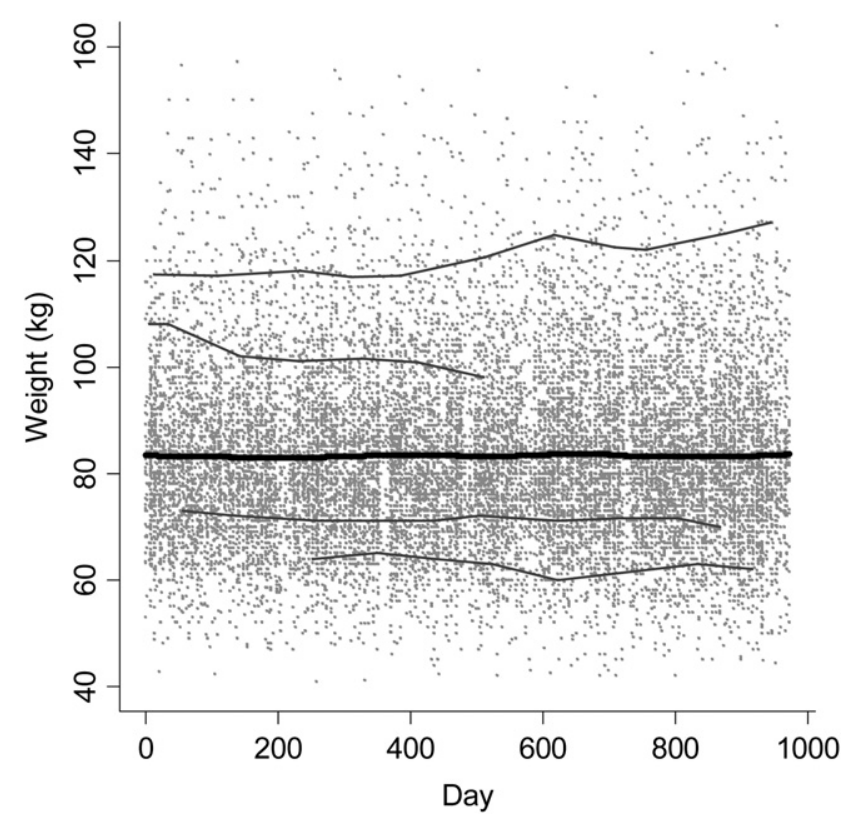

Fig. 3. Plot of repeated measurements of weight over time. Thick black line: loess smoother to visualize the model-free overall trend of the weight data. Thin black lines: illustration of the course of weight over time of four patients. 


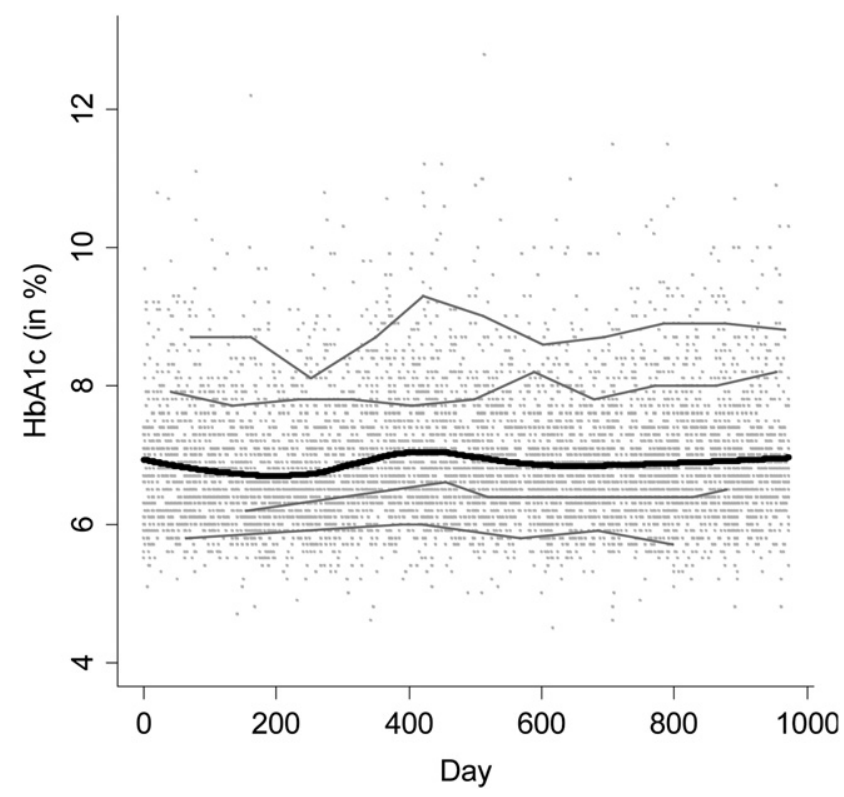

Fig. 4. Plot of repeated measurements of $\mathrm{HbAlc}$ over time. Thick black line: loess smoother to visualize the model-free overall trend of the HbAlc data. Thin black lines: illustration of the course of $\mathrm{HbAlc}$ over time of four patients.

less) weight during the observation period, whereas patients between the ages 30 and 70 tended to gain more (or lose less) weight. Patients who changed their PA level from "Deficient to Sportive" lost on average more weight (i.e., $4.33 \mathrm{~kg}$ more weight loss over 972 days) when compared with patients who stayed at a "Deficient" level $(P=$ 0.004). In fact, patients with this PA-change level lost statistically significant more weight when compared with all other PA-change levels (all $P<0.018$ ), except for patients who changed their PA level from "Healthy to Sportive" $(P=0.057)$ (data not shown in the table). Finally, most of the random variability in intercepts and slopes could be attributed to the patient as opposed to the general practitioner level of the model. In particular, $99.1 \%$ of the variability in the intercepts and $98.7 \%$ of the variability in the slopes were because of differences between patients (data not shown in the table).

For the analyses of changes of HbA1c over time, we included 1,615 patients (Fig. 1). The results from the multilevel model for HbA1c are shown in Table 2. The estimated average $\mathrm{HbA} 1 \mathrm{c}$ for 70 -year old male patients with an initial PA level of "Deficient" was $6.87 \%$ at the beginning of the observation period. Younger patients had a higher stating HbA1c compared with elderly $(+0.07 \%$ for every 10 years below the age of 70; $P<0.001)$. Patients who had their first measurement of $\mathrm{HbA1c}$ later in the follow-up period had a lower starting value than patients who had their first measurement earlier during the period (i.e., $-0.15 \%$ for patients who had the first measurement halfway through the observation period $(0.5 \mathrm{x}-0.30 \%)$ compared with those who had the first measurement at the first day of the period;
$P=0.013)$. Patients with a "Deficient" initial PA level had on average a $+0.14 \%$ higher starting HbA1c than those with a "Healthy" initial PA level $(P<0.001)$ and a $+0.23 \%$ higher starting HbA1c than those with a "Sportive" initial PA level $(P=0.004)$. The starting value did not depend on the gender of the patient $(P=0.102)$.

Change in the average HbA1c was not statistically significant during the observation period $(+0.03 \%$ over 972 days; $P=0.657)$. Again, a quadratic effect of age on the slope appeared to be present in the data $(P=0.038)$, with $\mathrm{HbA1c}$ tending to decrease more (or increase less) for patients between 71 and 93 years of age and tending to increase more (or decrease less) for patients below or above that range. Gender had no statistically significant effect on the slope $(P=0.531)$. Patients who improved their PA level from "Deficient to Sportive" or from "Deficient to Healthy" decreased their HbA1c significantly $(-0.72 \%$; $P=0.006$ and $-0.25 \% ; P=0.003$, respectively). In fact, in patients with PA-change level "Deficient to Sportive," HbA1c decreased significantly more when compared with the other PA-change levels (all $P<0.024$ ), except for patients who changed their PA level from "Deficient to Healthy" $(P=0.080)$ and from "Healthy to Sportive" $(P=0.289)$ (data not shown in the table). Finally, the random variability in the intercepts and slopes was again mostly attributable to differences between patients and not general practitioners $(95.8 \%$ and $97.4 \%$ for the intercepts and slopes, respectively: data not shown in the table).

\section{Discussion}

\subsection{Summary of results}

We evaluated the effects of the currently provided care for patients with T2DM in primary care on the course of weight and $\mathrm{HbA1c}$. We found that the average weight did not change during the observation period of 972 days, neither did average HbA1c. In addition, most of the patients did not change their PA level. Most patients did not exercise enough, and only a few patients exercised more than the minimum healthy level. Only in a subgroup of patients who improved their PA level, we found statistically significant positive trends of weight and $\mathrm{HbAlc}$. Any differences in the course of weight and $\mathrm{HbAlc}$ were predominantly influenced by random variability at the patient level; health care providers seemed to have very little influence.

\subsection{Comparison with existing literature}

When the results of our study on the course of weight and HbA1c are compared with those of the control group in lifestyle trials, it shows that changes in weight $[10,33-36]$ and HbA1c [10,33-35] in controls in these trials also are usually small and not statistically significant. However, usual care in a clinical trial setting may not be the same as the usual care in real-world primary care. The use of the electronic primary 
Table 2. Results from the multilevel model for weight and $\mathrm{HbA1C}$

\begin{tabular}{|c|c|c|c|c|}
\hline \multirow[b]{2}{*}{ Covariates } & \multicolumn{2}{|l|}{ Weight } & \multicolumn{2}{|l|}{ HbA1c } \\
\hline & Coefficient (95\% CI) (in kg) & $P$ & Coefficient (95\% CI) (in \%) & $P$ \\
\hline Intercept & 88.669 (87.234 to 90.104$)$ & $<0.001$ & $6.872(6.774$ to 6.971$)$ & $<0.001$ \\
\hline Day of first measurement ${ }^{a}$ & $-1.104(-4.612$ to 2.404$)$ & 0.537 & $-0.303(-0.082$ to -0.014$)$ & 0.013 \\
\hline \multicolumn{5}{|l|}{ Gender } \\
\hline Male & 0 & & 0 & \\
\hline Female & $-7.916(-9.272$ to -6.560$)$ & $<0.001$ & $-0.067(-0.147$ to 0.013$)$ & 0.102 \\
\hline $\operatorname{Age}^{\mathrm{b}}$ & $-3.980(-4.555$ to -3.405$)$ & $<0.001$ & $-0.065(-0.100$ to -0.030$)$ & $<0.001$ \\
\hline \multicolumn{5}{|l|}{ Initial PA level } \\
\hline Deficient & 0 & & 0 & \\
\hline Healthy & $-3.772(-5.173$ to -2.370$)$ & $<0.001$ & $-0.140(-0.223$ to -0.056$)$ & 0.001 \\
\hline Sportive & $-1.199(-3.896$ to 1.499$)$ & 0.384 & $-0.231(-0.390$ to -0.072$)$ & 0.004 \\
\hline \multicolumn{5}{|l|}{ Slope } \\
\hline Day (after first measurement) ${ }^{a}$ & $0.071(-0.583$ to 0.724$)$ & 0.832 & $0.027(-0.092$ to 0.146$)$ & 0.657 \\
\hline \multicolumn{5}{|l|}{ Gender } \\
\hline Male & 0 & & 0 & \\
\hline Female & $-0.048(-0.614$ to 0.517$)$ & 0.868 & $0.035(-0.074$ to 0.456$)$ & 0.531 \\
\hline $\mathrm{Age}^{\mathrm{b}}$ & $-0.773(-1.052$ to -0.493$)$ & $<0.001$ & $-0.066(-0.117$ to -0.016$)$ & 0.010 \\
\hline$\left(\mathrm{Age}^{2}\right)^{\mathrm{b}}$ & $-0.191(-0.357$ to -0.025$)$ & 0.024 & $0.029(-0.243$ to 0.300$)$ & 0.038 \\
\hline \multicolumn{5}{|l|}{ PA-change level } \\
\hline Deficient $\rightarrow$ Deficient & 0 & & 0 & \\
\hline Deficient $\rightarrow$ Healthy & $-0.682(-1.641$ to 0.277$)$ & 0.163 & $-0.252(-0.416$ to -0.089$)$ & 0.003 \\
\hline Deficient $\rightarrow$ Sportive & $-4.326(-7.286$ to -1.367$)$ & 0.004 & $-0.723(-1.238$ to -0.208$)$ & 0.006 \\
\hline Healthy $\rightarrow$ Deficient & $0.265(-0.608$ to 1.137$)$ & 0.552 & $0.111(-0.041$ to 0.264$)$ & 0.154 \\
\hline Healthy $\rightarrow$ Healthy & $-0.530(-1.241$ to 0.180$)$ & 0.143 & $-0.109(-0.241$ to 0.023$)$ & 0.105 \\
\hline Healthy $\rightarrow$ Sportive & $-0.628(-3.148$ to 1.893$)$ & 0.625 & $-0.367(-0.796$ to 0.061$)$ & 0.093 \\
\hline Sportive $\rightarrow$ Deficient & $0.737(-1.522$ to 2.997$)$ & 0.522 & $0.164(-0.235$ to 0.563$)$ & 0.421 \\
\hline Sportive $\rightarrow$ Healthy & $-0.095(-1.650$ to 1.459$)$ & 0.904 & $0.091(-0.188$ to 0.371$)$ & 0.522 \\
\hline Sportive $\rightarrow$ Sportive & $1.147(-0.683$ to 2.978$)$ & 0.219 & $-0.029(-0.368$ to 0.310$)$ & 0.868 \\
\hline
\end{tabular}

Abbreviation: $\mathrm{Cl}$, confidence interval.

Reference: male, 70 years old, initial PA level "Deficient," PA-change level "Deficient $\rightarrow$ Deficient."

a Day of first measurement and day (after first measurement) per 972 days.

b Age centered at 70 years and per 10 years.

care records makes it possible to investigate the effects of usual care without the Hawthorne-like effects that could be expected in analyses of research settings [23].

To really achieve lifestyle effects in routine primary care, effective experimental lifestyle programs should become usual care within time. Translation studies [22] and the results of this article show that lifestyle programs in usual care settings are not as successful as the programs in clinical trial settings. There may be several reasons for this lack of translation of evidence from trial setting into the daily primary care setting. One reason may be that it is very difficult for policy makers to work with evidencebased medicine when it comes to nonpharmacological interventions. It may be difficult to find or choose that specific trial applicable for a certain situation, even with the availability of systematic reviews [25]. Another reason may be that there is little time for health care providers for lifestyle management in daily practice, because of the current structure of the diabetes management programs, which focus on diabetes indicators and medical treatment and not on lifestyle.

In type 2 diabetics, exercise may have positive effects on $\mathrm{HbAlc}$ levels, but it is uncertain to what extent exercise really influences weight in diabetic patients $[5,8,37]$. It has been shown that exercise has beneficial effects on healthrelated outcomes and glycemic control, independent from changes in body weight $[5,38]$. However, our results show that more people decrease than increase their PA level and that only a very limited number of patients have a higher PA level than minimally required. Therefore, patients may not achieve sufficiently high PA levels to improve health outcomes. Previous research showing that exercise programs in primary care have limited effects on increasing PA [39-42] confirms the lack of effectiveness of such programs in real-world settings.

\subsection{Strengths and limitations}

This study is not a fully comprehensive research to investigate the effectiveness of all lifestyle programs in primary care. Nor is this manuscript a complete solution to the problems of translating evidence from trial settings into realworld primary care. This study is only part of the puzzle. Other research questions are imaginable, such as how much of the available evidence is at least considered for implementation in primary care. In addition, we did not fully investigate all pros and cons of using electronic medical records for research. We propose a feasible method to use 
these data to evaluate the effectiveness of real-world primary care. Nevertheless, we do suggest that this manuscript highlights the importance, the difficulties, and maybe some solutions of these issues that both daily practice and daily research struggle with.

Because we used the electronic primary care records for data abstraction, missing values were inevitable. We had no data on PA of 610 patients. This could bias the results if the assessment depended on the outcome measurement (i.e., missing data may be missing not at random). However, all centers used the same diabetes management program, which describes in detail the variables that should be measured and when they should be measured. When patients significantly improve their PA level, they presumably would have little reason to withhold that information from their health care provider. Besides, patients tend to overestimate their PA level. Therefore, it is more likely that the results are false positive rather than false negative. The small number of patients within the "Sportive" PA level may indicate a realistic distribution into categories.

Our results show that patients in subgroups who improved their PA level lost weight and lowered their HbA1c. However, we cannot conclude that these improvements were caused by their increase in exercise. It is likely that these patients improved multiple facets of their lifestyle and not only the amount of exercise. Besides, we did not take medication use into account. Because our results show that the currently provided care is able to stabilize HbA1c levels without improving PA levels and weight, we can assume that medication usage influenced HbAlc levels.

We did not include a control condition in our evaluation. As we wanted to evaluate real-world usual care for all type 2 diabetics, we did not differentiate between (preventive) lifestyle programs that could have started implementing in practice during the observational period. In addition, some [39] but probably not all individual programs could be made visible when using only data from electronic primary care records. Therefore, we cannot rule out that some evidence from trials did translate into routine daily care and that the situation would have been worse otherwise. Now that electronic primary care records are available and the registration is adequate, future studies should show whether the situation changes over the years.

\section{Conclusions}

Currently provided care for patients with T2DM in primary care stabilizes but not decrease weight and HbA1c. In addition, most patients remain physically inactive. There is an evidence gap between effective lifestyle interventions in clinical trial settings and real-world primary care. Therefore, to really intervene in the growing pandemic of diabetes, the real challenge is to develop and implement effective lifestyle programs in primary care. To demonstrate the actual effectiveness of lifestyle interventions in primary care, future studies should take place in primary care networks with solid medical registration systems.

\section{Acknowledgments}

The authors thank L.G. Gidding for helping with the data abstraction.

\section{References}

[1] Danaei G, Finucane MM, Lu Y, Singh GM, Cowan MJ, Paciorek CJ, et al. National, regional, and global trends in fasting plasma glucose and diabetes prevalence since 1980: systematic analysis of health examination surveys and epidemiological studies with 370 countryyears and 2.7 million participants. Lancet 2011;378:31-40.

[2] Finucane MM, Stevens GA, Cowan MJ, Danaei G, Lin JK, Paciorek CJ, et al. National, regional, and global trends in body-mass index since 1980: systematic analysis of health examination surveys and epidemiological studies with 960 country-years and $9 \cdot 1$ million participants. Lancet 2011;377:557-67.

[3] Wild S, Roglic G, Green A, Sicree R, King H. Global Prevalence of Diabetes. Estimates for the year 2000 and projections for 2030. Diabetes Care 2004;27:1047-53.

[4] Roglic G, Unwin N, Bennett PH, Mathers C, Tuomilehto J, Nag S, et al. The burden of mortality attributable to diabetes: realistic estimates for the year 2000. Diabetes Care 2005;28:2030-5.

[5] Boulé N, Haddad E, Kenny G, Wells G, Sigal R. Effects of exercise on glycemic control and body mass in type 2 diabetes mellitus: a metaanalysis of controlled clinical trials. JAMA 2001;286:1218-27.

[6] Delahanty LM, Nathan DM. Implications of the diabetes prevention program and Look AHEAD clinical trials for lifestyle interventions. J Am Diet Assoc 2008;(108):S66-72.

[7] Orozco LJ, Buchleitner AM, Gimenez-Perez G, Roqué I Figuls M, Richter B, Mauricio D. Exercise or exercise and diet for preventing type 2 diabetes mellitus. Cochrane Database Syst Rev 2008;(3):CD003054.

[8] Thomas DE, Elliott EJ, Naughton GA. Exercise for type 2 diabetes mellitus. Cochrane Database Syst Rev 2006;(3):CD002968.

[9] Knowler WC, Barrett-Connor E, Fowler SE, Hamman RF, Lachin JM, Walker EA, et al. Reduction in the incidence of type 2 diabetes with lifestyle intervention or metformin. N Engl J Med 2002;346:393-403.

[10] Pi-Sunyer X, Blackburn G, Brancati FL, Bray GA, Bright R, Clark JM, et al. Reduction in weight and cardiovascular disease risk factors in individuals with type 2 diabetes: one-year results of the look AHEAD trial. Diabetes Care 2007;30:1374-83.

[11] Tuomilehto J, Lindström J, Eriksson JG, Valle TT, Hämäläinen H, Ilanne-Parikka $\mathrm{P}$, et al. Prevention of type 2 diabetes mellitus by changes in lifestyle among subjects with impaired glucose tolerance. N Engl J Med 2001;344:1343-50.

[12] Dixon JB, O'Brien PE, Playfair J, Chapman L, Schachter LM, Skinner S, et al. Adjustable gastric banding and conventional therapy for type 2 diabetes: a randomized controlled trial. JAMA 2008; 299:316-23.

[13] Absetz P, Valve R, Oldenburg B, Heinonen H, Nissinen A, Fogelholm M, et al. Type 2 diabetes prevention in the "real world": one-year results of the GOAL Implementation Trial. Diabetes Care 2007;30:2465-70.

[14] Ackermann RT, Finch EA, Brizendine E, Zhou H, Marrero DG. Translating the Diabetes Prevention Program into the community. The DEPLOY Pilot Study. Am J Prev Med 2008;35:357-63.

[15] Amundson HA, Butcher MK, Gohdes D, Hall TO, Harwell TS, Helgerson SD, et al. Translating the diabetes prevention program into practice in the general community: findings from the Montana Cardiovascular Disease and Diabetes Prevention Program. Diabetes Educ 2009;35:209-10. 13, 14, 16-23. 
[16] Fleming P, Godwin M. Lifestyle interventions in primary care: systematic review of randomized controlled trials. Can Fam Physician 2008;54:1706-13.

[17] Helmink JH, Meis JJ, de Weerdt I, Visser FN, de Vries NK, Kremers SP. Development and implementation of a lifestyle intervention to promote physical activity and healthy diet in the Dutch general practice setting: the BeweegKuur programme. Int J Behav Nutr Phys Act 2010;7:49.

[18] Kilkkinen A, Heistaro S, Laatikainen T, Janus E, Chapman A, Absetz P, et al. Prevention of type 2 diabetes in a primary health care setting. Interim results from the Greater Green Triangle (GGT) Diabetes Prevention Project. Diabetes Res Clin Pract 2007;76:460-2.

[19] Saaristo T, Moilanen L, Korpi-Hyövälti E, Vanhala M, Saltevo J, Niskanen L, et al. Lifestyle intervention for prevention of type 2 diabetes in primary health care: one-year follow-up of the Finnish National Diabetes Prevention Program (FIN-D2D). Diabetes Care 2010;33:2146-51.

[20] Schwarz PEH, Lindström J, Kissimova-Scarbeck K, Szybinski Z, Barengo NC, Peltonen M, et al. The European perspective of type 2 diabetes prevention: diabetes in Europe-prevention using lifestyle, physical activity and nutritional intervention (DE-PLAN) project. Exp Clin Endocrinol Diabetes 2008;116:167-72.

[21] Vadstrup ES, Frølich A, Perrild H, Borg E, Røder M. Lifestyle intervention for type 2 diabetes patients: trial protocol of The Copenhagen Type 2 Diabetes Rehabilitation Project. BMC Public Health 2009; 9:166.

[22] Cardona-Morrell M, Rychetnik L, Morrell SL, Espinel PT, Bauman A. Reduction of diabetes risk in routine clinical practice: are physical activity and nutrition interventions feasible and are the outcomes from reference trials replicable? A Systematic Review and meta-analysis. BMC Public Health 2010;10:653.

[23] Gale EA. The Hawthorne studies-a fable for our times? QJM 2004; 97:439-49.

[24] Black N. Why we need observational studies to evaluate the effectiveness of health care. BMJ 1996;312:1215-8.

[25] Koppenaal T, Linmans J, Knottnerus JA, Spigt M. Pragmatic vs. explanatory: an adaptation of the PRECIS tool helps to judge the applicability of systematic reviews for daily practice. J Clin Epidemiol 2011;64:1095-101.

[26] Van Spall HGC, Toren A, Kiss A, Fowler RA. Eligibility criteria of randomized controlled trials published in high-impact general medical journals: a systematic sampling review. JAMA 2007;297:1233-40.

[27] Cebul RD, Love TE, Jain AK, Hebert CJ. Electronic health records and quality of diabetes care. N Engl J Med 2011;365:825-33.

[28] Shephard E, Stapley S, Hamilton W. The use of electronic databases in primary care research. Fam Pract 2011;28:352-4.

[29] van Weel C, de Grauw W. Family practices registration networks contributed to primary care research. J Clin Epidemiol 2006;59:779-83.
[30] Cleveland WS, Devlin SJ. Locally weighted regression: an approach to regression analysis by local fitting. J Am Stat Assoc 1988; 83:596-610.

[31] Tan F. Multilevel analysis of longitudinal data: syllabus. The Netherlands: Department of Methodology and Statistics, University of Maastricht; 2010.

[32] Pinheiro J, Bates D. Mixed-effects models in S and S-PLUS. New York: Springer; 2009.

[33] Andrews R, Cooper A, Montgomery A, Norcross A, Peters T, Sharp D, et al. Diet or diet plus physical activity versus usual care in patients with newly diagnosed type 2 diabetes: the Early ACTID randomised controlled trial. Lancet 2011;378:123-39.

[34] Knowler WC, Fowler SE, Hamman RF, Christophi CA, Hoffman HJ, Brenneman AT, et al. 10-year follow-up of diabetes incidence and weight loss in the Diabetes Prevention Program Outcomes Study. Lancet 2009;374:1677-86.

[35] Lindström J, Louheranta A, Mannelin M, Rastas M, Salminen V, Eriksson J, et al. The Finnish Diabetes Prevention Study (DPS): lifestyle intervention and 3-year results on diet and physical activity. Diabetes Care 2003;26:3230-6.

[36] Salopuro TM, Saaristo T, Oksa H, Puolijoki H, Vanhala M, Ebeling T, et al. Population-level effects of the national diabetes prevention programme (FIN-D2D) on the body weight, the waist circumference, and the prevalence of obesity. BMC Public Health 2011;11:350.

[37] Umpierre D, Ribeiro PAB, Kramer CK, Leitão CB, Zucatti ATN, Azevedo MJ, et al. Physical activity advice only or structured exercise training and association with HbA1c levels in type 2 diabetes: a systematic review and meta-analysis. JAMA 2011;305:1790-9.

[38] Church TS, LaMonte MJ, Barlow CE, Blair SN. Cardiorespiratory fitness and body mass index as predictors of cardiovascular disease mortality among men with diabetes. Arch Intern Med 2005;165: 2114-20.

[39] Linmans JJ, Spigt MG, Deneer L, Lucas AE, de Bakker M, Gidding LG, et al. Effect of lifestyle intervention for people with diabetes or prediabetes in real-world primary care: propensity score analysis. BMC Fam Pract 2011;12:95.

[40] Simons-Morton D, Blair S, King A, Morgan T, Applegate W, O'Toole M. Effects of physical activity counseling in primary care: the Activity Counseling Trial: a randomized controlled trial. JAMA 2001;286:677-87.

[41] Vermunt PWA, Milder IEJ, Wielaard F, de Vries JHM, van Oers HAM, Westert GP. Lifestyle counseling for type 2 diabetes risk reduction in Dutch primary care: results of the APHRODITE study after 0.5 and 1.5 years. Diabetes Care 2011;34:1919-25.

[42] Williams NH, Hendry M, France B, Lewis R, Wilkinson C. Effectiveness of exercise-referral schemes to promote physical activity in adults: systematic review. Br J Gen Pract 2007;57:979-86. 